\title{
POTENSI JASA LINGKUNGAN PADA KAWASAN TAMAN WISATA ALAM KLAMONO, KABUPATEN SORONG
}

\section{(The Potency of Ecosystem Services in Klamono Nature Park, District of Sorong)}

\author{
Akwila Johanes Kurey ${ }^{1}$ Yohanes Y. Rahawarin ${ }^{1 \bowtie}$ dan Dominggas M.H. Renwarin ${ }^{1}$ \\ Jurusan Kehutanan, Fakultas Kehutanan Universitas Papua Manokwari, Papua Barat, \\ 98314. Tlp/Fax: +62986211065. \\ ${ }^{\square}$ Penulis Korespondensi: Email: jo.rahawarin@gmail.com \\ Diterima: 15 Mei 2019| Disetujui: 01 Juli 2019
}

\begin{abstract}
Abstrak
Penelitian ini bertujuan untuk mengetahui jenis - jenis komoditi dan bentuk aktifitas pemanfaatan jasa lingkungan pada kawasan Taman Wisata Alam Klamono. Metode yang digunakan adalah metode deskriptif dengan teknik observasi dan wawancara. Observasi dilakukan terhadap komoditi jasa lingkungan yang ada pada kawasan Taman Wisata Alam Klamono dan wawancara dilakukan pada masyarakat di Kampung Klawana. Hasil penelitian menunjukkan bahwa komoditi jasa lingkungan terdiri atas a). potensi sumber air yang meliputi sungai Klagene dan sungai Klawana. b). Keanekaragaman hayati meliputi potensi flora dan potensi fauna c). Penyerapan karbon meliputi tumbuhan berkayu dan tumbuhan non kayu d). Panorama bentang alam. Aktivitas pemanfaatan jasa lingkungan meliputi sumber pemanfaatan tata air, flora, fauna, tumbuhan berkayu, tumbuhan non kayu dan panorama bentang alam. Potensi pengembangan jasa lingkungan dapat dinilai dengan mengunakan kriteria penilaian daya tarik, aksesibilitas, kondisi sosial ekonomi masyarakat, keamanan pengelolaan, dan sarana prasarana. Hasil skoring mengindikasikan bahwa Taman Wisata Alam Klamono dapat dikembangkan tetapi perlu pertimbangan beberapa aspek strategis oleh pemerintah setempat.
\end{abstract}

Kata kunci: jasa lingkungan, wisata alam, keanekaragaman hayati, flora fauna, penyerapan karbon

\begin{abstract}
This study works toward varieties of commodity and types of ecosystem service usage activity in Klamono nature park. The study has applied descriptive method through observation and interview techniques. The observation is focusing on the ecosystem service commodities in surrounding area and interview is carried out towards the local inhabitants of Klawana village. The result pointed out that ecosystem services consist of a). water resource potency that covered Klagene and Klawana rivers, b). natural resource, in particular the potency of flora and fauna, c). carbon absorption from woody and non woody plant species in the nature park, d). landscape panorama. The usage activities of ecosystem services covered water use, flora, fauna, woody and non woody plants, as well as ecosystem landscape. The prospect of ecosystem service development can be assessed by applying criteria such as attractiveness, accessibility, socio-economy status of the inhabitant community, management security, and facilities and infrastructure. Scoring
\end{abstract}


results indicated that Klamono nature park can be developed, however it required a number of strategic considerations by the local government.

Keywords: ecosystem service, natural tourism, natural resource, flora fauna, carbon absorption

\section{PENDAHULUAN}

Hutan merupakan salah satu sumberdaya alam yang multifungsi dalam menunjang kehidupan umat manusia yang tidak hanya terbatas sebagai tempat konservasi keanekaragaman hayati dan pemeliharaan fungsi ekosistem, tetapi juga menghasilkan barang dan jasa bagi masyarakat (Rahawarin 2010).

Hutan sangat penting bagi kehidupan di muka bumi, terutama bagi kehidupan generasi mendatang. Kesalahan dalam pengelolaan hutan berarti menyiksa kehidupan generasi mendatang. Untuk mencegah kesalahan dalam pengelolaan hutan, maka fungsi hutan harus dipelajari dan dimengerti secara holistik (utuh). Pengelolaan hutan bukan hanya sekedar menetapkan hutan sebagai perlindungan tanah, iklim, sumber daya air dan pemenuhan kebutuhan akan kayu dan produk lainya. Namun, pengelolaan hutan harus ditujukan untuk mendayagunakan semua lahan demi kepentingan negara, bahkan dunia (Arief 2005).

Salah satu wilayah di Indonesia yang memiliki sumber daya hutan yang paling potensial adalah Papua. Formasi hutan papua kaya akan jenis, general dan famili khas yang tidak dijumpai pada formasi lain dan dapat dijadikan tanaman berguna bagi manusia. Jumlah flora papua diperkirakan 20.000-25.000 jenis dengan keendemikan diperkirakan antara 60-90\% (Johns 1997; Lekitoo et al. 2017). Terdapat 124 marga tanaman berbunga endemis, bila dibandingan dengan 59 marga endemis di Kalimantan; 17 marga endemis di Sumatera dan 10 marga endemis di pulau Jawa. Sejauh ini telah diketahui 154 jenis mamalia, dimana 93 jenis merupakan endemis yang terdiri atas 41 jenis dari kalangan monotremata dan marsupialia, serta 52 jenis dari kalangan kelelawar dan binatang pengerat (Petocz 1987). Potensi yang begitu tinggi membutuhkan upaya perlindungan, pengawetan dan pemanfaatan yang lestari untuk menjaga keanekaragamannya.

Kawasan konservasi selain berfungsi sebagai kawasan yang dilindungi, juga mempunyai fungsi lain sebagai sistem penyangga kehidupan dan sebagai sarana kegiatan pengembangan penelitian dan ilmu pengetahuan, pendidikan, wisata alam dan penunjang budidaya. Upaya melestarikan sumberdaya alam hayati dan ekosistemnya bukan hanya menjadi tanggung jawab pemerintah tetapi merupakan tanggung jawab semua lapisan masyarakat. Hal ini sesuai dengan amanat Undang-Undang Nomor 41 tahun 1999 pasal 68 ayat 1 dan 2 serta pasal 29 ayat 1 yang menyatakan bahwa masyarakat selain mempunyai hak menikmati kualitas lingkungan hidup yang dihasilkan hutan, memanfaatkan hutan dan hasil hutan sesuai dengan peraturan yang berlaku, tetapi juga berkewajiban ikut serta dalam menjaga kawasan hutan dari gangguan dan kerusakan (Pangesti 2005). Tujuan dari penelitian ini antara lain untuk mengetahui jenis-jenis komoditi jasa lingkungan, mengetahui aktivitas pemanfaatan komoditi jasa lingkungan 
dan mengkaji kemungkinan pemanfaatan jasa lingkungan di kawasan Taman Wisata Alam Klamono (TWAK).

\section{METODE PENELITIAN}

\section{Tempat dan Waktu}

Penelitian ini dilaksanakan di areal Taman Wisata Alam Klamono Kabupaten Sorong dengan lamanya waktu penelitian sekitar 3 minggu, yaitu dari tanggal 26 Januari - 16 Februari tahun 2019. Yang menjadi obyek dalam penelitian ini adalah potensi jasa lingkungan pada kawasan TWAK, sementara subyek penelitian adalah masyarakat yang berada pada kampung disekitar kawasan TWAK.

\section{Metode dan Teknik Penelitian}

Penelitian ini dilakukan dengan menggunakan metode deskriptif dengan teknik observasi lapang dan wawancara. Observasi dilakukan terhadap komoditi jasa lingkungan yang ada pada kawasan TWAK, sedangkan wawancara dilakukan terhadap masyarakat yang memanfaatkan jasa lingkungan.

\section{Variabel Penelitian}

Variabel yang diamati dalam pelaksanaan penelitian ini meliputi: jenis komoditi jasa lingkungan, aktivitas pemanfaatan jasa lingkungan, dan kemungkinan pengembangan pemanfaatan jasa lingkungan.

\section{Pelaksanaan Penelitian}

\section{Penentuan Responden}

Penentuan responden dibagi menjadi dua yaitu responden kunci (key respondent) dan responden umum (common respondent). Responden kunci terdiri dari aparat kampung sebanyak 2 orang dan tokoh masyarakat sebanyak 3 orang sehingga total responden kunci sebanyak 5 orang. Responden umum adalah masyarakat yang tinggal di kampung Klawana. Jumlah responden yang diwawancarai sebanyak $30 \%$ dari total jumlah masyarakat Kampung Klawana sebanyak $110 \mathrm{KK}$ yang berada di sekitar kawasan TWAK.

\section{Teknik Pengumpulan Data}

Data yang dikumpulkan terdiri atas data primer dan data sekunder. Data primer dikumpulkan dengan teknik observasi, dokumentasi dan wawancara. Data primer meliputi: jenis komoditi jasa lingkungan, keberadaan jasa lingkungan, lokasi timbulnya jasa lingkungan yang dihasilkan, dan kegiatan pemanfaatan jasa lingkungan. Data sekunder dikumpulkan dengan cara pencatatan dan dokumentasi dari instansi terkait serta studi pustaka berupa laporan penelitian yang berkaitan dengan topik penelitian.

\section{Pengelolaan dan Analisis Data}

Data yang dikumpulkan dianalisis mengunakan kriteria penelitian potensi obyek dan daya tarik alam yang telah dimodifikasi dari pedoman kriteria penilaiaan pengembangan (Direktorat Jendral Perlindungan Hutan dan Konservasi Alam, Departemen Kehutanan, 2003/dan Direktorat Produk Wisata Direktorat Jendral Destinasi Pariwisat Departemen Kebudayaan dan Pariwisata 2007). Kemudian data yang dianalisis diuraikan dan ditampilkan dalam bentuk tabel dan gambar.

Kriteria yang dinilai adalah daya tarik, aksesbilitas, kondisi lingkungan dan sosial masyarakat, keamanan dan pengelolaan, sarana dan prasarana. Pada setiap kriteria memiliki nilai dan bobot. Nilai setiap kriteria (S) yang diperoleh dari hasil akan dikalikan dengan bobot (B) kriteria dengan jumlah nilai 
unsurunsur kriteria $(\mathrm{N})$. jumlah nilai unsur-unsur kriteria diperoleh dari nilai yang sudah ada pada tabel penilaiaan yang disesuaikan dengan kondisi dan karakter lokasi obyek penelitian dan dapat dihitung mengunakan rumus seperti berikut :

$$
\mathbf{S}=\mathbf{B} \times \mathbf{N}
$$

Keterangan :

$$
\begin{array}{ll}
\mathrm{S} & =\text { Nilai kriteria } \\
\mathrm{B} & =\text { Bobot nilai kriteria }
\end{array}
$$

$\mathrm{N}=$ Jumlah nilai unsur unsur kriteria

Penilaian potensi jasa lingkungan berdasarkan modifikasi dari Pedoman Kriteria Penilaiaan Pengembangan Direktorat Jendral Perlindungan Hutan dan Konservasi Alam, Departemen Kehutanan (2003) dan Direktorat Produk Wisata Direktorat Jendral Destinasi Pariwisat Departemen Kebudayaan dan Pariwisata (2007), dengan kriteria penilaian seperti pada tabel 1 .

Tabel 1. Daftar kriteria penilaian jasa lingkungan yang telah dimodifikasi

No. Unsur yang dinilai Bobot

\begin{tabular}{lll}
\hline 1. & Daya tarik & 6 \\
2. & Aksesibilitas & 5 \\
3. & Kondisi lingkungan sosial ekonomi masyarakat & 5 \\
4. & Keamanan dan pengelolaan & 3 \\
5. & Sarana dan prasarana & 3 \\
\hline
\end{tabular}

Selanjutnya hasil penelitian akan dikategorikan berdasarkan nilai selang, dimana selang yang ditetapkan dikategorikan dalam 3 kategori, yaitu: baik, sedang dan buruk. Nilai selang akan dihitung dari rumus :

Selang $(\mathrm{S})=\mathrm{S} \max -\mathrm{S} \min /$

$$
\text { Banyaknya kategori }
$$

Nilai maximum akan diperoleh dari jumlah total skor tertinggi, sedangkan nilai minimum diperoleh dari jumlah total skor terendah. Hasil perhitungannya berupa kategori dan selang penilaian potensi jasa lingkungan pada kawasan TWAK.

Tabel 2. Kategori selang penilaiaan potensi jasa lingkungan kawasan TWAK

\begin{tabular}{lll}
\hline No. & Kategori & Interval/Selang \\
\hline 1. & Buruk & $1090-1600$ \\
2. & Sedang & $1601-2110$ \\
3. & Baik & $2111-2620$ \\
\hline
\end{tabular}

Kategori dan interval/selang diambil sebagai acuan standarisasi untuk menentukan layak dan tidaknya suatu obyek yang akan dikembangkan sebagai obyek wisata alam. Kriteria penilaiaan masuk dikategorikan sebagai berikut :

a. Kategori Buruk berarti bahwa potensi jasa lingkungan pada TWAK tidak dapat dikembangkan. 
b. Kategori Sedang berarti bahwa potensi jasa lingkungan dapat dikembangkan dan masih diperlukan pertimbangan kembali dari pemerintah.

c. Kategori Baik berarti bahwa potensi jasa lingkungan pada kawasan TWAK harus dikembangkan sebagai nilai keunggulan bagi kabupaten sorong.

Data yang dikumpulkan diolah secara tabulasi dan dianalisis secara deskriptif dan selanjutnya ditampilkan dalam bentuk tabel dan gambar/foto.

\section{HASIL DAN PEMBAHASAN}

\section{Jenis Komoditi Jasa Lingkungan}

Berdasarkanhasil observasi lapangan pada kawasan TWAK jenis komoditi jasa lingkungan meliputi yang ditemukan berupa: 1). tata air, 2). keanekaragaman hayati, 3). penyerapan karbon, dan 4). bentuk-bentuk pemanfaatan sumber daya alam dan jasa lingkungan. Berikut ini merupakan karakteristik dari masing masing jenis komoditi jasa lingkungan:

\section{Tata air}

Berdasarkan hasil pengamatan terdapat sumber air yang berada di dalam kawasan TWAK, diperoleh informasi berupa keberadaan sungai Klagene dan sungai Klawana yang merupakan sungai-sungai yang mengalir di dalam kawasan TWAK. Sungai Klagene dan sungai Klawana adalah merupakan anak sungai dari sungai induk pada Distrik Klamono yaitu sungai Klasofot.

Sungai Klagene berasal dari mata air yang berada di luar kawansan TWAK yang tepatnya di bawah kaki gunung Mariat dan mengalir di dalam kawasan sampai bermuara pada sungai induk sungai Klasifot atau yang biasa di sebut sungai induk Klamono. Keberadaan sungai Klagene dapat di lihat dari jalan raya Sorong - Klamono tepatnya di Kilometer 37.

Sama seperti sungai Klagene, sungai Klawana juga merupakan sungai yg mengalir melewati kawasan TWAK. Kondisi sungai yang masih alami dengan banyaknya vegetasi berada di sepanjang kiri dan kanan sungai. Di sebut sungai Klawana karena sungai ini adalah sungai yang mengalir keluar dari TWAK ke kampung Klawana.

\section{Keanekaragaman Hayati}

Kekayaan keanekaragaman hayati merupakan salah satu potensi pada aspek jasa lingkungan yang berpontensi dikembangkan sebagai parawisata dan ekowisata. Selain itu, terdapat juga kawasan konservasi yang memiliki potensi cukup tinggi yang tersebar di berbagai tipe ekosisitem yang terdapat di dalam kawasan TWAK. Potensi lingkungan yang berada di dalam kawasan TWAK berupa panorama alam, berbagai jenis flora dan fauna serta beberapa sungai yang mengalir di dalam kawasan. Potensi tersebut merupakan potensi untuk menunjang kegiatan wisata alam.

\section{Flora}

Berbagai jenis tumbuhan di dalam kawasan ini merupakan jenis-jenis yang umumnya tumbuh di hutan dataran rendah. Kegiatan inventarisasi telah dilakukan di dalam kawasan TWAK (Maturbongs 2011) dengan perolehan data berdasarkan tingkatannya yaitu tingkat semai ditemukan sebanyak 102 jenis, pancang 102 jenis, dan pohon 102 jenis. Dari jenis data tersebut diperoleh nilai INP pada masing-masing tingkat vegetasi yang berbeda. Untuk tingkat semai, Cleytanthus papuana memiliki nilai INP tertinggi yakni $16,649 \%$, 
kemudian diikuti oleh jenis Dillenia indica dan Vileburna rubescent masingmasing dengan nilai INP $10,841 \%$ dan $10,202 \%$. Untuk tingkat pancang, jenis yang memiliki INP tertinggi adalah Cleytanthus papuana dengan 15,580\%, kemudian disusul oleh jenis Sphatiostemon javaensis dengan nilai INP $12,845 \%$ dan jenis Villebrunea rubescent dengan nilai INP $12,674 \%$. Sementara untuk tingkat pohon, jenis yang memiliki nilai INP tertinggi adalah Artocarpus altilis dengan nilai $25,695 \%$, disusul oleh jenis Pometia pinnata dengan nilai INP $24,199 \%$ dan jenis Teijsmaniodendron bogoriense dengan nilai INP 14,031\%.

Fauna

Terdapat potensi berbagai jenis satwa khususnya jenis-jenis yang telah dilindungi undang- undang seperti Kakatua Jambul Kuning (Cacatua galerita triton), Kakatua Raja (Proboscinger aterrimus), Nuri Merah Kepala Hitam (Lorius lory), Cenderawasih (Paradiseae spp.), Kasuari (Casuarius casuarius), Rusa (Rusa timorensis) dan Kangguru Pohon (Dendrolagus sp.).

\section{Penyerapan Karbon}

Potensi jasa lingkungan berupa penyerapan karbon merupakan salah satu jasa penting dalam kawasan konservasi yang juga berperan menyediakan oksigen da udara segar dari dalam kawasan TWAK. Dengan hadirnya berbagai jenis vegetasi hutan di Kawasan TWAK, memberikan potensi ketersediaan oksigen dan udara segar yang melimpah. Hasil identifikasi di lapangan, terdapat dua kelompok tubuhan yang petensial sebagai penyerap karbondioksida dan selanjutnya sebagai agen penyedia oksigen.
Tumbuhan Berkayu (woody plant)

Hasil pengamatan langsung yang dapat di amati dalam Kawasan TWAK, terdapat berbagai jenis tumbuhan berkayu, yang sebagai penyerap karbon dan penyedia oksigen. Terdiri dari 49 jenis tumbuhan berkayu dari 26 family yang terdapat di Kawasan TWAK Untuk menunjang jasa linkungan dan perlindungan kawasan Konsevasi dalam peningkatan tempat wisata TWAK terdapat tiga jenis famili tumbuhan berkayu yaitu, Fabaceae, Sapindaceae, dan Moraceae, yang dominan dalam kawasan TWAK. Jenis jenis tumbuhan berkayu yang ditemukan memiliki potensi daya tarik yang sangat menarik baik dari karakter morfologi daun, batang, bunga dan buah. Pesona ini menjadi suatu hal yang unik dan jarang ditemukan ditempat lainnya. Hal ini di tunjukan dengan kelangkaan dan endemiknya jenis-jenis yang ditemukan pada kawasan tersebut. Jenis - jenis tumbuhan berkayu yang ditemukan beserta daya tarik jasa linkungan antara lain: Artocarpus altilis, Pometia pinnata, Teijsmaniodendron bogoriense, Ficus pungens, Melanolepis multiglandulosa, Ficus trachypison, Cleytanthus papuana, Artocarpus odoratasimus, Trichospermum javanicum, Macaranga mapa, Spatiostemon javensis, Melanolepis multiglandulosa, Canarim sp., Vileburna rubescen, dan Dillenia indica.

Tumbuhan Bukan Kayu (non woody plant)

Komposisi tumbuhan non kayu pada kawasan TWAK Kabupaten Sorong antara lain: rotan, palem, pandan, bambu, anggrek, paku-pakuan, herba dan liana yang merupakan tumbuhan non potensial sebagai peyerap karbon dan menyediakan oksigen untuk menujang potensi jasa 
lingkungan dan perlindungan kawasan konservasi pada kawasan TWAK. Secara detail, jenis-jenis tumbuhan bukan kayu yang ditemukan antara lain dari jenis rotan (Calamus aruensis Bacc., Calamus kayensis Bacc., Korthalsia), dari jenis palm (Arenga macrocalyx Ex., Aracea sp., caryato rumpicna Mart., Licuala telifera., Licuala sp., Metroxilon sagoo Rotbb., Pigafeta filaris, Pinanga punicea, Rhopaloblaste sp.), jenis pandanus (Pandanus tectorius Sol., Pandanus furcatus Roxb., Pandanus conoides Lam., Pandanus odoratissimus, Freycinetia sp.), jenis bambu (Bambusa vurgaris, Schozostacchyum brachyclaudum Kurz., Schozostachyum lima, Schozostachyum zollingeri, neolaleba atra) dan jenis anggrek (Bullbophyllum sp., Calanthe sp., Colagyne asperata, Corimborkis veratrifolia, Dendrabium bofalce, Dendrobium bracteosum, Gramatophyllum scriptum BL., Gramatophyllum speciosum LINDL., Phalaenopsis amabilis, Pholidota imbricatai, Pomotocalpa sp., dan Spothoglottis plicata BL.).

\section{Pemanfaatan Tata Air}

Pemanafaatan tata air pada sungai Klagene telah dilakukan oleh masyarakat Kampung Klawana dan Wonosari. Sungai Klagene hanya dimanfaatkan sebagai patokan atau batas alam, yang memisahkan hak ulayat pada kawasan TWAK dari 2 marga suku Moy yaitu marga Mambringgofok dan Osok. Pemanfaatan tata air pada sungai Klawana juga dapat dilakukan oleh masyarakat Kampung Klawana dan Wonosari, namun sungai Klawana hanya dimanfaatkan sebagai tapal batas kedua kampung tersebut. Selain itu belum ada pemanfaatan lain yang dilakukan oleh masyarakat maupun Balai Konservasi Sumberdaya Hutan (BKSDH). Sejauh ini hanya dilakukan kegiatan pengawasan dan perlindungan oleh pemerintah dan pemegang hak ulayat.

\section{Pemanfaatan Keanekaragaman Hayati}

\section{Bird Watching}

Mengamati burung (bird watching) secara langsung di dalam hutan merupakan kegiatan wisata alam yang dapat memberikan pengetahuan. Selain itu pengunjung juga dapat melakukan pengambilan gambar/foto dari obyekobyek satwa tersebut. Kegiatan bird watching di dalam TWAK dapat dilakukan dengan mengunjungi spot-spot pengamatan burung. Terdapat berbagai macam jenis burung yang dapat dijumpai di dalam dan sekitar kawasan termasuk jenis burung endemik seperti jenis Kakatua Jambul Kuning (Cacatua galerita triton), Kakatua Raja (Proboscinger aterrimus) Nuri Merah Kepala Hitam (Lorius lory).

Jungle Tracking

Kawasan TWAK menyediakan jalur tracking alam yang memikat. Di sepanjang jalur track, pengunjung dapat menikmati suasana alam dan udara yang segar, selain itu disepanjang jalur track bisa mengenal berbagai macam jenis tumbuhan endemik TWAK serta dapat berjumpa dengan satwa langka yang menarik dari beberapa jenis burung paruh bengkok yang ada di Papua.

\section{Fishing}

Terdapat beragam jenis ikan air tawar yang berada di sungai Klagewe di Kawasan TWA Klamono. Kegiatan memancing (fishing) merupakan salah satu kegiatan wisata alam yang dapat di lakukan kepada pengunjung. Hal menarik yang dapat dilakukan yaitu sambil 
memancing pengunjung dapat menikmati keindahan alam, Tetapi pada pelaksanaan sendiri belum adanya pengelolaan yg baik dari pemanku kepentingan (stakeholder) dalam menentuan arah kebijakan pemanfaatan dan pengembangan Taman Wisata Alam Klamono.

\section{Pengembangan Pemanfaatan Jasa Lingkungan}

Kelayakan pengembangan dilakukan melalui beberapa kriteria untuk mengambarkan karakteristik potensi wisata alam yang layak dikembangkan atau sebeliknya belum dapat di kembangkan. Potensi wisata alam pada kawasan Taman Wisata Alam Klamono meliputi 5 (lima) kriteria, yaitu daya tarik, aksesibilitas, kondisi lingkungan sosial ekonomi masyarakat, keamanan dan pengelolaan dan sarana dan prasarana.

Daya tarik merupakan nilai dari obyek yang menjadi salah satu unsur utama dalam menarik wisatawan datang ke tempat tertentu. Penilaian terhadap unsurunsur daya tarik di lakukan untuk mengetahui potensi daya tarik TWAK yang di nilai meliputi unsur keindahan alam, keunikan sumber daya alam, banyaknya sumber daya alam yang menojil, serta jenis kegiatan wisata alam. Dari skoring yang dilakukan, diperoleh nilai 450 yang masuk kategori cukup tinggi.

Aksesibilitas merupakan salah satu faktor penting yang menentukan mudah atau tidaknya wisatawan datang ke daerah tujuan wisata misalnya sarana trasportasi dan jalan. Dari aksebilitas, TWAK di tunjang dengan aksesibilitas yang memadai (725) $\mathrm{k}$ arena mudan di akses mengunakan kendaraan mobil atau motor dengan waktu tempuh yang relatif cepat. Kondisi jalan darat yang cukup baik dari pusat kota kabupaten menuju kawasan TWAK dengan waktu tempuh 2-4 jam tergantung kendaraan darat apa yg digunakan.

Dari kondisi lingkungan sosial ekonomi masyarakat sekitar juga sangat berperan penting dalam penyeimbangan potensi jasa lingkungan . unsur - unsur yang dinilai dari kondisi sosial ekonomi masyarakat antara lain: tata ruang wilayah objek, mata pencaharian, tingkat Pendidikan, dan tanggapan masyarakat terhadap pengembangan TWAK. Kondisi sosial ekonomi masyarakat sekitar berdasarkan hasil wawancara bahawa masyarakat pada kampung klawana cukup mendukung dengan (nilai 375) karena adanya sikap positif yang di tujukan oleh masyarakat sekitar.

Keamanan dan pengelolaan kawasan adalah salah satu hal penting dalam melestarikan potensi jasa lingkungan yang berada pada kawasan TWAK. Penilaian keamanan dan pengelolaan dalam kawasan dapat dinilai dgn kriteria penilaian sebagai berikut: keamanan Kawasan yang meliputi kebakaran, penebangan liar, perambahan, keamanan pengunjung dan pengolahan kawasan. Dari aspek keamanan dan pengelolaan di beri (nilai 240) dari segi keamanan masih kurang baik, karena masih adanya aktifitas manusia pada kawasan yang menyebapkan kebakaran akibat pembukaan lahan, penebangan liar yang di lakukan besar besaran dari dalam maupun di luar kawasan TWAK, oleh para pemilik hak ulaiyat maupun dari luar dengan.

Sarana penunjang yang sangat diperlukan dalam menjalankan kegiatan wisata alam dengan tujuan memberikan rasa aman dan nyaman bagi pengunjung. Unsur-unsur kriteria sarana dan prasarana 
yang dinilai yaitu unsur sarana berupa rumah makan, sarana angkutan umum dan prasarana berupa jalan, jembatan, jaringan listrik, jaringan air minum dan jaringan telepon. Hasil penilaian sarana dan prasarana yg di nilai di sini adalah sarana dan prasarana yang berada di sekitar TWAK atau yang terdapat pada kampung klamono sedangkan pada kawasan TWAK sendiri belum adanya perhatian daan aktifitas aktifitas pada kawasanTWAK. Sarana dan prasarana (nilai 135) sarana rumah makan dan sarana angkot umum dapat diakses dengan mudah sebelum kita mengunjungi TWAK. Sedangkan prasarana seperti jalan, jembatan, jaringan listrik, jaringan air minum, dan jaringan telepon dapat membantu kita untuk sampai pada kawasan TWAK.

Hasil rekapitulasi nilai terhadap 5 unsur penilaian yang terlah di modifikasi modifikasi dari Pedoman Kriteria Penilaiaan Pengembangan Direktorat Jendral Perlindungan Hutan dan Konservasi Alam, Departemen Kehutanan (2003) dan Direktorat Produk Wisata Direktorat Jendral Destinasi Pariwisat Departemen Kebudayaan dan Pariwisata adalah sebesar 1925, yang terdiri dari unsur daya tarik bernilai 450 , aksebilitas bernilai 725 , soaial ekonomi masyarakat sekitar bernilai 375, keamana dan pengelolaan bernilai 240 dan sarana prasarana bernilai 135. Berdasaran kategori dan selang penilaian, potensi jasa lingkungan kawasan TWAK tergolong pada kategori penilaian sedang (16012110). Hal ini berarti bahwa potensi jasa lingkungan pada kawasan TWAK dapat di kembangkan tetapi perlu pertimbangan kembali dari pemerintah. Berdasarkan hasil obserfasi lapangan dan wawancara dengan responden kunci dan responden umum yang berdomisili di Kampung Klawana, sebagian besar menyetujui apabila TWAK dikembangkan dan dilestarikan secara baik. Hal ini menjadi modal dasar yang tentunya untuk dikembangkan dimasa depan karena adanya persetujuan dan dukungan masyarakat setempat. Namun dimana saat ini dalam hal keamanan dan pengelolaan masih ada banyak terjadi pelanggaran misalnya penebangan liar yang di sengaja (ilegal logging), dan perambahan hutan (pengunaan lahan). Pengelolaan kawasan sendiripun belum ada misalnya pintu gerbang masuk kawasan, rambu rambu kawasan, pos penjagaan untuk keamanan kawasan. Selama ini dari pihak pemerintah dan balai besar konservasi sumberdaya hutan masih belum ada kesepakaan tentang status kawasan Taman Wisata Alam Klamono dengan pemegang hak ulayat (Mambringgofok). Sejauh ini justru baru diadakanya pendekatan seperti kegiatan dari BBKSDH melalui pembentukan kelompok tani hutan, mitra polhut di Kampung Klawana, Kampung Klamono dan Wonosari. Selain itu ada juga bantuan berupa ternak sapi pada tahun 2018, penangkaran buaya pada tahun 2018, pembibitan pada tahun 2018, dan pelatihan RHL, dalam bentuk uang tunai ataupun secara lansung diberikan. Oleh karena itu di harapkan kepada pemerintah setempat dan Balai Besar Konservasi Sumberdaya Hutan Provinsi Papua Barat untuk dapat mengembangkan dan meningkatkan aspek pengelolaan Kawasan terutama pengamanannya di sekitar kawasan TWAK.

\section{DAFTAR PUSTAKA}

Arief A. 2005. Hutan dan kehutanan. Penerbit Kansius, Yogyakarta. 
BBKSDA Papua Barat. 2007. Buku Informasi Kawasan Bidang KSDA Wilayah I Sorong. Balai Besar Konservasi Sumberdaya Alam Papua Barat. Sorong.

Departemen Kehutanan. 1999. UndangUndang Nomor 41 Tahun 1999. Pemerintah Republik Indonesia, Jakarta.

Departemen Kehutanan. 2003. Pedoman analisis daerah operasi objek dan daya tarik wisata alam (ADO-ODTWA). Direktorat Jendral Perlindingan Hutan dan Konservasi alam. Bogor.

Departemen Kebudayaan dan Pariwisata. 2007. Pedoman penilaian daya tarik wisata. Direktorat Jenderal Pengembangan Destinasi Pariwisata.

Johns RJ. 1997. Biodiversity in Irian Jaya: Proposals for the listing of selected areas for priority conservation. (Disampaikan dalam Lokakarya Keanakragaman Hayati di Biak). Royal Botanical Gardens, Kew, Ricmond Surrey TW9, CAB England.
Lekitoo K, Peday HFZ, Panambe N and Cabuy RL. 2017. Ecological and ethnobotanical facet of 'Kelapa Hutan' (Pandanus spp.) and perspectives towards its existence and benefit. International Journal of Botany, 13: 103-114.

Maturbongs RG. 2011. Analisis kualitas obyek dan daya tarik wisata di Taman Wisata Alam Klamono Kabupaten Sorong. [Tesis]: Program Pascasarjana Universitas Gadjah Mada. Yogyakarta.

Pangesti T. 2005. Wisata alam. Materi pelatihan konservasi sumber daya hayati. Balai Diklat Kehutanan, Bogor.

Petocz RG. 1987. Konservasi alam dan pembangunan di Irian Jaya. Strategi Pemanfaatan Sumber Daya Alam Secara Rasional. PT. Temprint. Jakarta.

Rahawarin YY. 2010. Forest land use by the community in Sorong Natural Tourism Park at Sorong City, West Papua Province. Biodiversitas, Vol 11 (4): 222-227. 